\title{
Photoperiodism and seasonal adaptations in some seed-sucking bugs (Heteroptera) in central Japan
}

\author{
Hideharu NUMATA ${ }^{1}$ and KEIJI NAKAMURA ${ }^{2}$ \\ ${ }^{1}$ Department of Bio- and Geosciences, Graduate School of Science, Osaka City University, Osaka 558-8585, Japan; e-mail: \\ numata@sci.osaka-cu.ac.jp \\ ${ }^{2}$ Department of Chemistry, Faculty of Science, Okayama University of Science, Okayama 700-0005, Japan
}

Key words. Photoperiodic response, critical daylength, adult diapause, seed-sucking bugs, Heteroptera, Pentatomidae, Alydidae

\begin{abstract}
Photoperiodic responses and their adaptive significance were examined in Riptortus clavatus (Heteroptera: Alydidae), Plautia crossota stali, Dolycoris baccarum, Aelia fieberi, Nezara viridula, Nezara antennata, Graphosoma rubrolineatum, Dybowskyia reticulata, and Eurydema rugosum (Heteroptera: Pentatomidae) in the Kyoto-Osaka area, central Japan. All of these species overwinter as adults in diapause. Although they have similar feeding habits, their photoperiodic responses were quite different. Riptortus clavatus, P. c. stali, D. baccarum and N. viridula showed long-day photoperiodic responses with critical daylengths between 13 and $14 \mathrm{~h}$, and were assumed to have three generations per year. The photoperiodic responses of the other five species were different both from those of the above species and from each other. These results suggested that $A$. fieberi and $N$. antennata produce two generations per year, and G. rubrolineatum, D. reticulata and E. rugosum have one or two generations per year. Nezara antennata showed a long-day-short-day photoperiodic response with summer adult diapause, which may avoid production of heatsusceptible nymphs in the hottest season. With the exception of $N$. antennata, the photoperiodic responses resulting in fewer generations were shown to be adaptations to dietary conditions in the field.
\end{abstract}

\section{INTRODUCTION}

Since Danilevskii (1961) first showed geographical variations in photoperiodic responses and their ecological significance in insects, many studies have shown that there is a geographical cline in the critical daylength of photoperiodic responses. In insects with long-day photoperiodic responses for the induction of winter diapause, critical daylengths for the induction of diapause show a positive correlation with latitude. In higher latitude regions where winter arrives earlier, insects must enter diapause earlier, and therefore have longer critical daylengths (Danilevskii, 1961; Tauber et al., 1986; Danks, 1987). Consequently, although a few exceptions have been reported (e. g., Tauber \& Tauber, 1972, 1977), closely related species in the same locality are generally expected to have similar photoperiodic responses, with similar critical daylengths.

There are many heteropterans that feed on plant seeds in the Kyoto-Osaka area (about $35^{\circ} \mathrm{N}$ ), central Japan. This mini-review addresses whether they have similar photoperiodic responses and life cycles. Here, we describe photoperiodic responses in nine of these species and discuss their adaptive significance. All of these species overwinter as adults in diapause, and are classified as Pentatomidae, except Riptortus clavatus which belongs to the Alydidae. All observations in the field and the collection of insects for laboratory experiments were made in the Kyoto-Osaka area. In the following sections, "diapause incidence" is that of female adults.

\section{PHOTOPERIODIC RESPONSES AND LIFE CYCLES}

\section{The bean bug, Riptortus clavatus (Thunberg)}

This species feeds on the seeds of legumes and some other plants (Tomokuni et al., 1993; Panizzi et al., 2000a). In the Kyoto-Osaka area, $R$. clavatus produces three generations per year, and adults emerging in September enter diapause.

The induction of adult diapause is controlled by photoperiod. Under long-day conditions at $25^{\circ} \mathrm{C}$, female adults develop their ovaries promptly after emergence and lay eggs. Under short-day conditions, however, they enter diapause, with a suppression of ovarian development. Continuous darkness and extreme short-day conditions have effects similar to long-day conditions (Numata \& Hidaka, 1982).

We determined the photoperiodic response curve of $R$. clavatus at $25^{\circ} \mathrm{C}$, on two occasions, using insects from the same locality, i. e., the northern part of Kyoto City $\left(35.0^{\circ} \mathrm{N}, 135.8^{\circ} \mathrm{E}\right)$. Under $4 \mathrm{~L}: 20 \mathrm{D}$, none of the females entered diapause in the first experiment (Numata \& Hidaka, 1982), whereas $87 \%$ entered diapause in the second experiment (Kobayashi \& Numata, 1993). Although this response was classified as type III by Beck (1980), it is ecologically equivalent to a long-day photoperiodic response of type I, because no daylength shorter than $10 \mathrm{~h}$ is ever encountered by insects living in natural conditions (Tauber et al., 1986). The results under 4L : 20D were markedly different in the two experiments. This discrepancy probably reflects genetic variation between individuals, resulting from the absence of any selection pressure. 


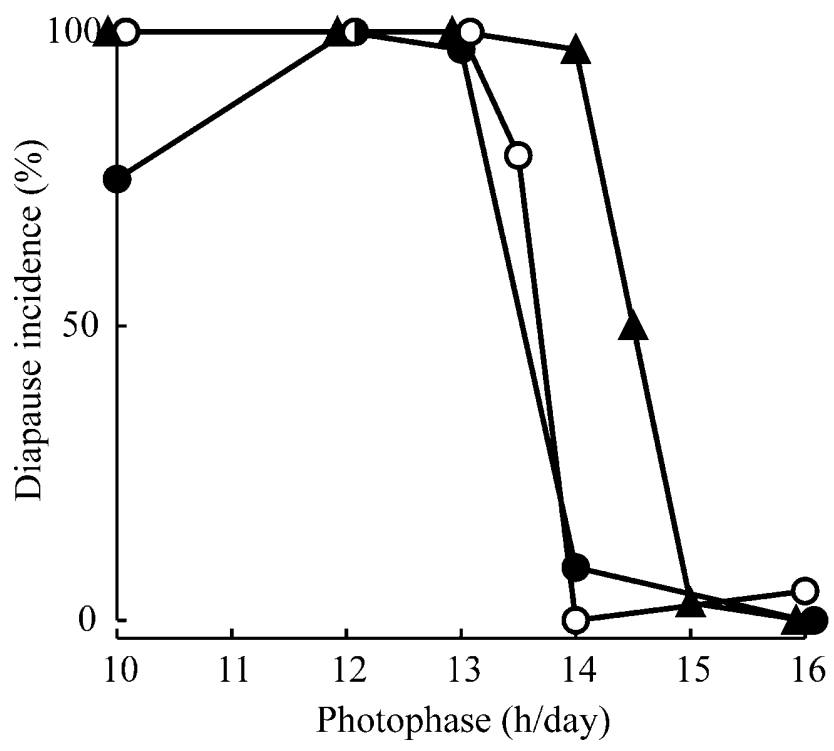

Fig. 1. Photoperiodic response curves for diapause induction in female adults of Riptortus clavatus in Kyoto (open circles [Kobayashi \& Numata, 1993], only the ecological range is shown), Plautia crossota stali in Tawaramoto (closed circles [Numata \& Kobayashi, 1994]), and Aelia fieberi in Osaka (triangles [Nakamura \& Numata, 1997]) at $25^{\circ} \mathrm{C}$.

Under the other photoperiodic conditions tested, however, there were no noticeable differences between the two experiments (Numata \& Hidaka, 1982; Kobayashi \& Numata, 1993), and the critical daylength in the ecological range was about $13.5 \mathrm{~h}$ at $25^{\circ} \mathrm{C}$ (Fig. 1). Although some adults failed to enter diapause even under short-day conditions at $30^{\circ} \mathrm{C}$, the critical daylength was stable at 20 , 25 , and $30^{\circ} \mathrm{C}$ (Kobayashi \& Numata, 1993). If we assume that this species responds to daylength including $0.5 \mathrm{~h}$ twilight in the field, the critical daylength is equivalent to the daylength at $35^{\circ} \mathrm{N}$ in late August, and this photoperiodic response explains the emergence of diapause adults in September in the field.

\section{The brown-winged green bug, Plautia crossota stali Scott}

This is a polyphagous species that feeds on the seeds of various plants, such as cherry, mulberry and cypress (Tomokuni et al., 1993; Panizzi et al., 2000b). The induction of adult diapause is controlled by photoperiod (Kotaki \& Yagi, 1987). The photoperiodic response curve was similar to that of $R$. clavatus and the ecologically critical daylength was also about $13.5 \mathrm{~h}$ at $25^{\circ} \mathrm{C}$ in a population from Tawaramoto, Nara Prefecture, $\left(34.5^{\circ} \mathrm{N}\right.$, $135.8^{\circ} \mathrm{E}$ ) (Numata \& Kobayashi, 1994). We assume that $P$. c. stali also produces three generations per year in the Kyoto-Osaka area, and that adults emerging in September enter diapause.

\section{The berry bug, Dolycoris baccarum (L.)}

This species is also polyphagous and feeds on the seeds of various plants, such as legumes, crucifers, grasses and composites (Tomokuni et al., 1993; Panizzi et al., 2000b). Babrakzai \& Hodek (1987) reported that adult diapause was induced by a short-day photoperiod in a Czech population of this species. Insects collected in Osaka City $\left(34.7^{\circ} \mathrm{N}, 135.5^{\circ} \mathrm{E}\right)$ also showed a long-day photoperiodic response, and the critical daylength was slightly longer than $13 \mathrm{~h}$ at $25^{\circ} \mathrm{C}$ (Nakamura \& Numata, in preparation). Although the critical daylength was a little shorter than those of $R$. clavatus and $P$. c. stali, the life cycle of $D$. baccarum in the Kyoto-Osaka area is considered to be similar to that of these two species.

\section{Aelia fieberi Scott}

This species feeds on the seeds of grasses (Tomokuni et al., 1993). The induction of adult diapause is controlled by a long-day photoperiodic response. However, the critical daylength for the induction of diapause was about $14.5 \mathrm{~h}$ at $25^{\circ} \mathrm{C}$ in a population from Osaka City (Fig. 1) (Nakamura \& Numata, 1997), which is longer by $1 \mathrm{~h}$ than those of $R$. clavatus and $P$. c. stali and corresponds to the daylength in late July at $35^{\circ} \mathrm{N}$, including $0.5 \mathrm{~h}$ twilight.

Our field observations, and an examination of ovarian development in field-collected insects, showed that A. fieberi produces two generations per year and that adults of the second generation enter diapause in August, although subsequent temperatures seemed to be sufficient to produce another generation. Some eggs were placed outdoors in August, when wild adults had already entered diapause, and the hatching nymphs were reared on wheat seeds. Adults emerged in September and early October, and most of them overwintered (Nakamura \& Numata, 1997). Therefore, temperature in autumn is not the factor that prevents reproduction by $A$. fieberi in August.

Seeding grasses were observed in the field from March to November, but no single plant species produced seeds throughout this period. We can clearly divide the observed plants into two groups. In one group, the seeds are produced in spring and early summer, i.e., Poa annua, Bromus catharticus, Agropyron tsukushiense, Dactylis glomerata, Lolium multiflorum and Avena fatua, whereas the plants in the other group produce seeds in summer and autumn, i.e., Setaria viridis, Eleusine indica and Digitaria ciliaris (Fig. 2) (Nakamura \& Numata, 1997). Although seeds of grasses were present continuously from early spring to late autumn, the identity of the main host plants in nature and the nutritive values of seeds of various grasses to $A$. fieberi were unclear. Therefore, nymphal development of $A$. fieberi was measured by feeding them on the seeds of various grasses under $12 \mathrm{~L}$ : $12 \mathrm{D}$ at $25^{\circ} \mathrm{C}$. Adults emerged successfully on the seeds of grasses producing seeds in spring and early summer within the exception of $A$. fatua. When reared on the seeds of grasses producing seeds in summer and autumn, however, most nymphs died in the second instar and no adults emerged (Fig. 2) (Nakamura \& Numata, 1997).

All suitable host species of grass produce their seeds exclusively in spring and early summer, and thus no suitable food is available for $A$. fieberi in autumn. Poor food availability in autumn appears to be the ultimate factor for determining diapause induction before September. In response to this selection pressure, $A$. fieberi has evolved a longer critical daylength for the induction of diapause. 


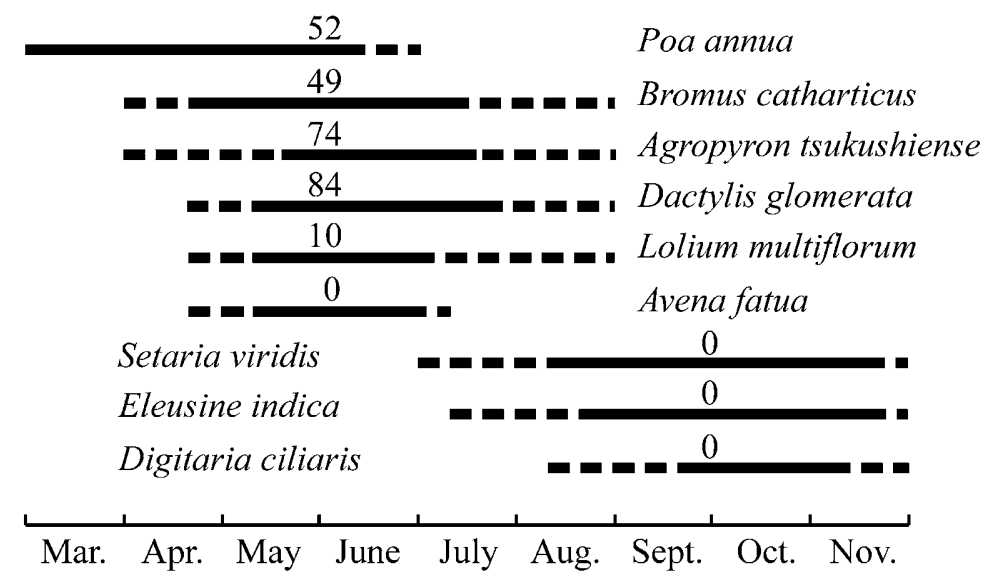

Fig. 2. Seasonal occurrence of grass seeds in the field in Osaka, Japan and their suitability as food for Aelia fieberi (altered from Nakamura \& Numata, 1997). Numerals indicate the percentage adult emergence when nymphs were reared on seeds from each species.

\section{The southern green stink bug, Nezara viridula (L.)}

This is a highly polyphagous species that feeds on seeds of various plants, such as legumes, grasses and crucifers (Todd, 1989; Tomokuni et al., 1993; Panizzi et al., 2000b). Nezara viridula has a worldwide distribution throughout tropical and subtropical regions (Todd, 1989; Panizzi et al., 2000b). It occurs only in the southern part of Japan, and the northern limit of its distribution in 1961-1962 was reported to be about $70 \mathrm{~km}$ south from Osaka City (Kiritani et al., 1963). However, this species is now common in Osaka City. Hence, over this period of 40 years, the species has extended its distribution northward.

Ali \& Ewiess (1977) showed a long-day photoperiodic response for the induction of adult diapause in an Egyptian population of $N$. viridula, and the critical daylength was about $12 \mathrm{~h}$ at $25^{\circ} \mathrm{C}$. Insects collected in Osaka City also showed a long-day photoperiodic response with a critical daylength slightly longer than $13 \mathrm{~h}$ at $25^{\circ} \mathrm{C}$. However, some adults reproduced even under $12 \mathrm{~L}: 12 \mathrm{D}$, and the results under $12 \mathrm{~L}: 12 \mathrm{D}$ and $13 \mathrm{~L}: 11 \mathrm{D}$ showed wide variation between three replicates of the experiment (Musolin \& Numata, in preparation). The critical daylength is similar to that for D. baccarum and slightly shorter than for $R$. clavatus and $P$. c. stali. The observation that reproduction is induced under $12 \mathrm{~L}: 12 \mathrm{D}$ in some individuals may reflect the subtropical origin of $N$. viridula and its recent invasion of this region.

However, it is still unclear whether adults of $N$. viridula overwinter in Osaka or migrate from overwintering sites further south, their progeny failing to survive in this region each winter.

\section{The Oriental green stink bug, Nezara antennata Scott}

This species is closely related to $N$. viridula, but it has a more northerly distribution in Japan (Kiritani et al., 1963). Nezara antennata produces two generations per year in the southern part of Wakayama Prefecture (Kiritani et al., 1963), and our field observations in Kyoto City were consistent with this.
Noda (1984) showed that a change from a long to a short photoperiod at adult emergence induced earlier oviposition in N. antennata in Ibaraki Prefecture, Japan. The photoperiodic response at $25^{\circ} \mathrm{C}$ was examined in insects collected in Kyoto City. In contrast to the above five species, adults of $N$. antennata entered diapause even under a long-day photoperiod. Only when adults were transferred from a long- to a short-day photoperiod was prompt oviposition induced. Thus, this species shows a long-dayshort-day photoperiodic response (Numata, unpublished). Because overwintering adults lay eggs in May and June (Kiritani et al., 1963), nymphs of the first generation develop under long-day conditions, enter summer diapause as adults, and begin to lay eggs only after a decrease in daylength. Then, nymphs of the second generation develop under short-day conditions, and enter winter diapause as adults. With this photoperiodic response, $N$. antennata produces the second generation only after the daylength becomes shorter, and hence this species never produces a third generation, even in an extraordinarily warm year. It is concluded that a longday-short-day photoperiodic response ensures a bivoltine life cycle in $N$. antennata.

Nezara antennata is also polyphagous, like $N$. viridula (Tomokuni et al., 1993; Panizzi et al., 2000b), which shows a long-day photoperiodic response and does not enter diapause in summer. It is, therefore, unlikely that summer diapause in $N$. antennata is related to the phenology of its host plants. In contrast to $N$. viridula, nymphs of this species are not tolerant of high temperatures, with a nymphal mortality of $68 \%$ at $30^{\circ} \mathrm{C}$ (Kariya, 1961). Therefore, the induction of summer diapause in response to a long-day photoperiod may serve to prevent useless production of nymphs in the hottest season.

\section{Graphosoma rubrolineatum (Westwood)}

This species feeds on the seeds of Umbelliferae (Tomokuni et al., 1993). The photoperiodic response of a population from Osaka City was examined. Some females showed a long-day photoperiodic response for the induc- 


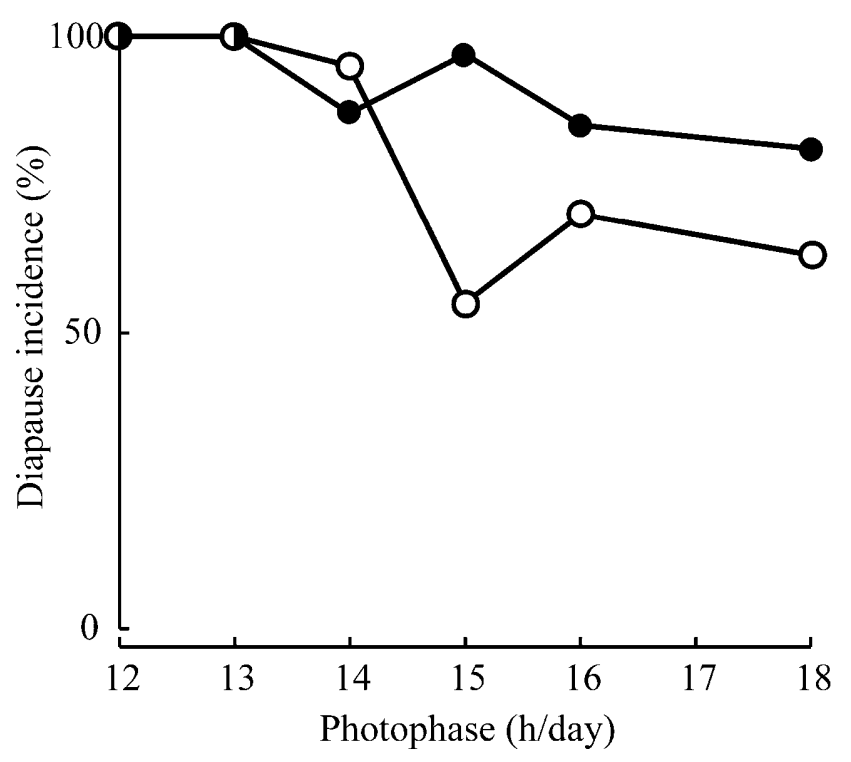

Fig. 3. Photoperiodic response curves for diapause induction in female adults of Graphosoma rubrolineatum in Osaka (open circles [Nakamura \& Numata, 1999]) and Dybowskyia reticulata in Osaka (closed circles [Nakamura \& Numata, 1998]) at $25^{\circ} \mathrm{C}$.

tion of adult diapause, and the critical daylength was about $14.5 \mathrm{~h}$ at $25^{\circ} \mathrm{C}$. However, more than $50 \%$ of female adults entered diapause under all photoperiodic conditions tested (Fig. 3) (Nakamura \& Numata, 1999). It was suggested, therefore, that some adults of the first generation that have developed under long-day conditions produce the second generation, whereas others enter diapause and overwinter.

In the plains of Osaka, Torilis japonica and T. scabra (Umbelliferae) produce seeds only in early summer, and these seeds have dried up and fallen to the soil by autumn. No other wild umbellifers were observed. Therefore, seeds of host plants are available only during a limited period around early summer. Therefore, the early induction of diapause in G. rubrolineatum is adapted to the subsequent absence of host seeds. However, the photoperiodic response does not reflect a strictly univoltine life cycle, but suggests that part of the population produces a second generation. As cultivated umbellifers such as Foeniculum vulgare sometimes produce seeds in midsummer or later, it is possible that adults of the first generation find such seeds and reproduce on them. Alternatively, reproductive adults may migrate to higher elevations where seeds of wild umbellifers are available longer than on the plains of Osaka.

As the critical daylength is about $14.5 \mathrm{~h}$ in individuals with a photoperiodic response, insects of the second generation develop under daylengths shorter than the critical value and enter diapause like those of $A$. fieberi. Therefore, we believe that $G$. rubrolineatum has a partially bivoltine life cycle in the Kyoto-Osaka area.

\section{Dybowskyia reticulata (Dallas)}

This species also feeds on the seeds of Umbelliferae (Tomokuni et al., 1993). The photoperiodic response was

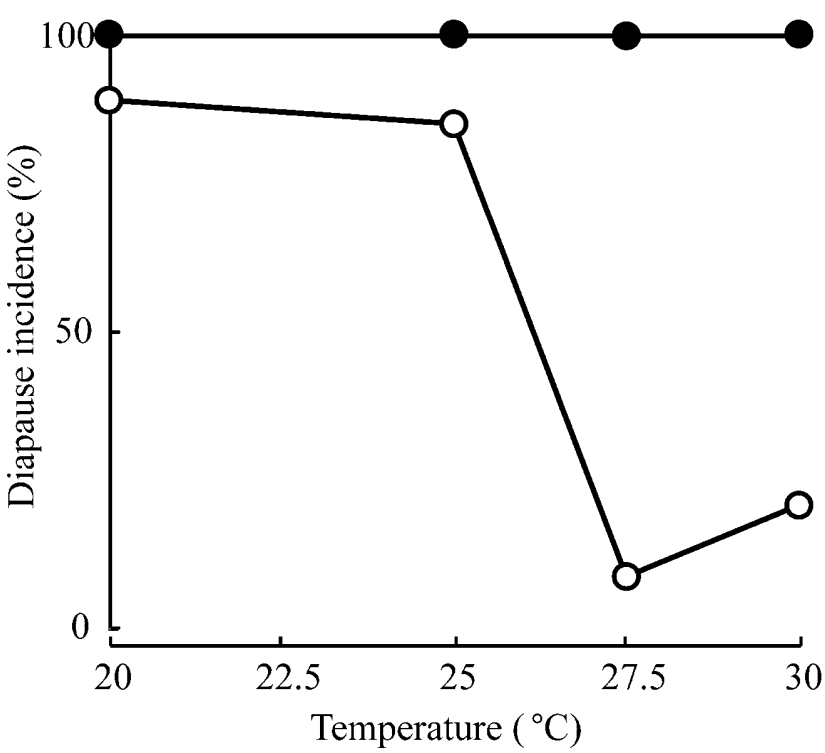

Fig. 4. Effects of temperature and photoperiod on diapause induction in female adults of Dybowskyia reticulata in Osaka (adapted from Nakamura \& Numata, 1998). Open circles, 16L $: 8 \mathrm{D}$; closed circles, $12 \mathrm{~L}: 12 \mathrm{D}$.

examined in insects collected in Osaka City. At $25^{\circ} \mathrm{C}$, more than $80 \%$ of female adults entered diapause under all photoperiodic conditions tested (Fig. 3) (Nakamura \& Numata, 1998). The results indicated that this species has a primarily univoltine life cycle.

At 27.5 and $30^{\circ} \mathrm{C}$, however, most adults raised under a long-day photoperiod of $16 \mathrm{~L}: 8 \mathrm{D}$ did not enter diapause, whilst those raised under a short-day photoperiod of $12 \mathrm{~L}$ : 12D entered diapause (Fig. 4) (Nakamura \& Numata, 1998). Therefore, D. reticulata shows a long-day photoperiodic response only at higher temperatures, and the threshold temperature was between 25 and $27.5^{\circ} \mathrm{C}$. When reared under outdoor conditions in 1993, when the summer temperatures were not very high, most adults of the first generation entered diapause in late July. However, in the warmer summer of 1996, oviposition was recorded in many females that emerged as adults from July to early August, when mean daily temperatures were always above the threshold (Nakamura \& Numata, 1998).

Therefore, although seeds of the host plants occur in a restricted period from early summer to early autumn, $D$. reticulata may produce a second generation in warmer years. It may then complete two generations whilst seeds of the host plants are available. The response to temperature with a threshold of between 25 and $27.5^{\circ} \mathrm{C}$, causes a switch between univoltine and bivoltine life cycles.

\section{The cabbage bug, Eurydema rugosum Motschulsky}

The host plants of E. rugosum are crucifers (Tomokuni et al., 1993; Panizzi et al., 2000b). Although the nymphs of the previous by discussed eight species develop only on the seeds of their host plants, the nymphs of $E$. rugosum develop not only on seeds, but also on the leaves of crucifers. When reared on the leaves of oilseed rape, Brassica napus, this species also showed a long-day pho- 


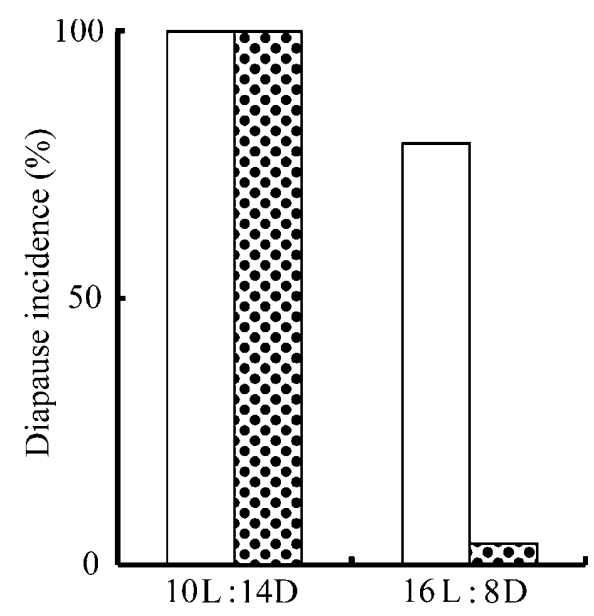

Fig. 5. Effect of food and photoperiod on diapause induction in female adults of Eurydema rugosum in Osaka at $25^{\circ} \mathrm{C}$ (altered from Numata \& Yamamoto, 1990). Seeds (open columns) or leaves (dotted columns) of oilseed rape were supplied as food.

toperiodic response for the induction of adult diapause at $25^{\circ} \mathrm{C}$. That is, most adults raised under $16 \mathrm{~L}: 8 \mathrm{D}$ became reproductive, whereas all adults entered diapause under $10 \mathrm{~L}: 14 \mathrm{D}$. When seeds of the same plant were given as food, however, all adults raised under 10L : 14D, and $79 \%$ of adults raised under $16 \mathrm{~L}: 8 \mathrm{D}$ entered diapause (Fig. 5) (Numata \& Yamamoto, 1990). In this species, therefore, not only photoperiod, but also dietary conditions play a decisive role in the induction of diapause. Although the photoperiodic response curve on leaves has not been determined in E. rugosum, the critical daylength is longer than $13 \mathrm{~h}$, because all adults entered diapause when raised on leaves of oilseed rape under 13L : 11D at $25^{\circ} \mathrm{C}$ (Ikeda-Kikue \& Numata, unpublished).

In the field, some crucifers bloom in early spring, their seeds mature, and either the whole plant dies by late spring, or the above-ground parts of most plants die in early summer. During summer, the vegetative parts of these species disappear. Other crucifers have green leaves all year round, and are continuously present as potential food sources for insects (Yano \& Ohsaki, 1993). In the field, first generation adults of E. rugosum emerged from mid-June and most entered diapause on brown mustard, Brassica juncea. This plant bloomed in early spring and the plants died by early summer. On the other hand, cultivated crucifers such as radish, Raphanus sativus var. hortensis, and cabbage, Brassica oleracea var. capitata, retained green leaves all year round. Most adults of the first generation reproduced on these plants and adults of the second generation emerging in September, entered diapause (Ikeda-Kikue \& Numata, 2001).

Eggs of E. rugosum were reared under natural conditions of photoperiod and temperature in Osaka City, in early May, when overwintering adults reproduced in the field. The nymphs were reared on seeds or leaves of oilseed rape. Adults emerged in late June on both seeds and leaves. Most adults raised on seeds entered diapause, whereas most adults raised on leaves reproduced as they were reared under a long-day photoperiod in the laboratory. Eggs were then placed under natural conditions of photoperiod and temperature in late July, when adults of the first generation were laying eggs in vegetable plots in the field. Leaves of oilseed rape were supplied as food. Adults emerged from late August, when the adults of the second generation emerged in the field, and most of them entered diapause (Ikeda-Kikue \& Numata, 2001).

These results indicate that diapause in E. rugosum is induced at different times of the year on different host plants, and thus the phenology of the host plants affects the life cycle of E. rugosum. Diapause induced on seeds under long-day conditions is not terminated by supplying leaves as a food source (Ikeda-Kikue \& Numata, 1994). It is unlikely, therefore, that diapause adults of the first generation, which have developed on brown mustard, migrate to other host plants and produce a second generation.

Therefore, E. rugosum shows either a univoltine or bivoltine life cycle, depending on the phenology of its host plant. When, after overwintering, adults lay eggs on host plants that bloom in early spring, mature their seeds and die by early summer, most adults of the first generation enter diapause. In contrast, when such adults lay eggs on host plants that have green foliage all year round, most adults of the first generation avoid diapause to produce a second generation, and all adults of the second generation enter diapause.

\section{DISCUSSION}

Fig. 6 summarizes the life cycles of the nine seedsucking bugs described above. Their life cycles are classified into three types based on the numbers of generations. The type A life cycle is characterized by three generations per year. Riptortus clavatus shows this type of seasonal pattern. This species has a long-day photoperiodic response with a critical daylength of about $13.5 \mathrm{~h}$, produces three generations per year, and enters diapause in September. Plautia crossota stali and D. baccarum show similar photoperiodic responses and probably have this type of life cycle. Although it is still unclear whether $N$. viridula is established already in the Kyoto-Osaka area, it shows a similar photoperiodic response and may produce three or more generations per year. The critical daylength for the induction of adult diapause is also between 13 and $14 \mathrm{~h}$ in Eysacoris ventralis (Pentatomidae) in Izumo $\left(35^{\circ} \mathrm{N}\right)$ (Noda \& Ishii, 1981) and Cletus punctiger (Coreidae) in Tsukuba $\left(36^{\circ} \mathrm{N}\right)$ (Ito, 1988). These species may also have the type A life cycle. Abiotic conditions in central Japan support this type of life cycle in seed-sucking bugs as long as there are no specific adverse conditions such as absence of suitable food or high temperatures lethal to the nymphs.

Type B is a bivoltine life cycle, and the life cycles of $A$. fieberi and $N$. antennata are in this category. However, patterns of seasonal development and photoperiodic response differ between these species. Thus, the type B life cycle is subdivided into type $B_{1}$ and type $B_{2}$ (Fig. 6). A. fieberi (type $\mathrm{B}_{1}$ ) has a longer critical daylength and 


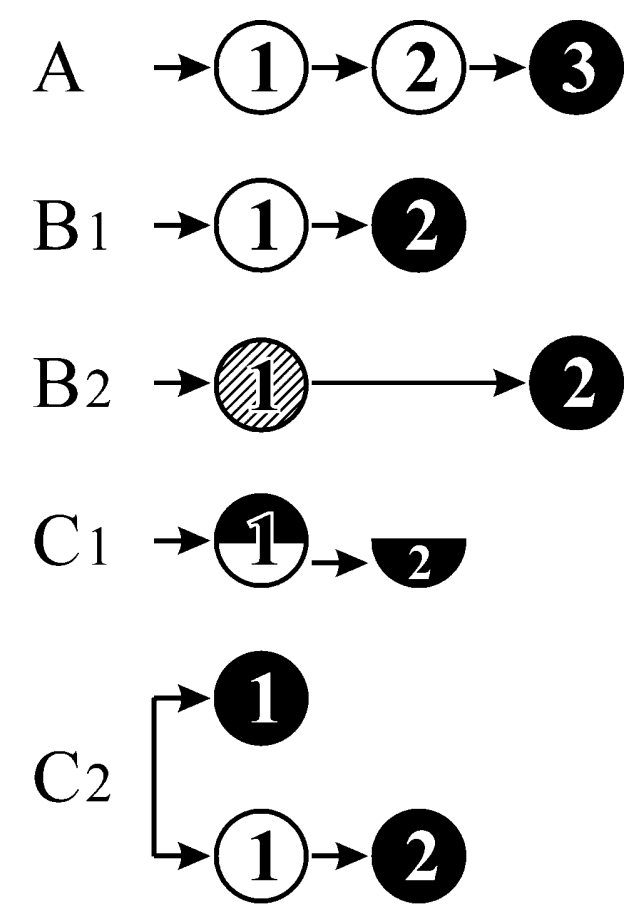

Fig. 6. Schematic representation of the life cycles of seedsucking bugs in central Japan. Numerals in circles indicate numbers of successive generations through the season. Black circles, overwintering generation; hatched circle, summer diapause. For further explanations, see text.

enters diapause earlier than the species with a type A life cycle. This early induction of diapause is an adaptation to the absence of suitable food sources in autumn. In contrast, $N$. antennata (type $\mathrm{B}_{2}$ ) shows a long-day-short-day photoperiodic response, with both summer and winter diapause in the adult stage. Because adults of the first generation enter summer diapause, adult emergence of the second generation is delayed until the period when adults of the third generation of the species with type A life cycles appear. This summer diapause seems to be an adaptation to adverse abiotic conditions.

The type $\mathrm{C}$ life cycle has one or two generations per year, and the life cycles of G. rubrolineatum, D. reticulata and E. rugosum are of this type. In G. rubrolineatum, only part of the population shows a long-day photoperiodic response. Some first generation adults produce a second generation, whereas others enter diapause and overwinter (type $\mathrm{C}_{1}$ ) (Fig. 6). Diapause and non-diapause adults may occur simultaneously in the same place. On the other hand, D. reticulata and E. rugosum alternate between univoltine and bivoltine life cycles (type $\mathrm{C}_{2}$ ) (Fig. 6). Both species switch between the two patterns, although the proximate factors determining this switch are different. In $D$. reticulata, adults of the first generation produce a second generation in warmer years, because high temperatures allow two generations within the restricted period when host plant seeds are available. In this species, the number of generations differs between years. However, the number of generations of E. rugosum depends on the phenology of the plants on which the adults lay eggs after overwintering, because development on leaves averts diapause in the subsequent adults, whereas adults raised on seeds enter diapause. This is an adaptation to the two patterns of host plant phenology.

In conclusion, closely related species of seed-sucking bugs from the same locality do not always have similar photoperiodic responses with similar critical daylengths (Tauber et al., 1986). Five of the nine species discussed here have life cycles that are different from the most common pattern (type A). The ultimate factor responsible for the production of less than three generations per year seems to be related to dietary conditions, except in $N$. antennata. These results therefore emphasize the importance of dietary constraints in the evolution of life cycles (Masaki, 1980; Danks 1987).

\section{REFERENCES}

Ali M. \& EwIEss M.A. 1977: Photoperiodic and temperature effects on rate of development and diapause in the green stink bug, Nezara viridula L. (Heteroptera: Pentatomidae). Z. Ang. Entomol. 84: 256-264.

BABRAKZAI Z.H. \& HoDEK I. 1987: Diapause induction and termination in a population of Dolycoris baccarum (Heteroptera: Pentatomoidea) from Central Bohemia. Vest. Cs. Spolec. Zool. 51: 85-88.

Beck S.D. 1980: Insect Photoperiodism, 2nd edn. Academic Press, New York, 387 pp.

Danilevski A.S. 1961: Photoperiodism and Seasonal Development of Insects. Leningrad State University Press, Leningrad (in Russian) [English Translation 1965: Oliver \& Boyd, Edinburgh, 283 pp.]

Danks H.V. 1987: Insect Dormancy: An Ecological Perspective. Biological Survey of Canada, Ottawa, 439 pp.

IKEDA-KIKUE K. \& Numata H. 1994: Effect of low temperature on the termination of photoperiodic and food-mediated diapause in the cabbage bug, Eurydema rugosa Motschulsky (Heteroptera: Pentatomidae). Appl. Entomol. Zool. 29: 229-236.

Ikeda-Kikue K. \& Numata H. 2001: Timing of diapause induction in the cabbage bug Eurydema rugosum (Heteroptera: Pentatomidae) on different host plants. Acta Soc. Zool. Bohem. 65: 197-205.

Iто K. 1988: Diapause termination in Cletus punctiger Dallas (Heteroptera: Coreidae) in the field. Jpn. J. Appl. Entomol. Zool. 32: 63-67. [in Japanese, English abstr.]

KARIYA H. 1961: Effects of temperature on the development and the mortality of the southern green stink bug, Nezara viridula and the Oriental green stink bug, N. antennata. Jpn. J. Appl. Entomol. Zool. 5: 191-196. [in Japanese, English abstr.]

Kiritani K., Hokyo N. \& Yukawa J. 1963: Co-existence of the two related stink bugs Nezara viridula and N. antennata under natural conditions. Res. Popul. Ecol. 5: 11-22.

Kobayashi S. \& Numata H. 1993: Photoperiodic responses controlling the induction of adult diapause and the determination of seasonal form in the bean bug, Riptortus clavatus. Zool. Sci. 10: 983-990.

KotaKi T. \& YAGI S. 1987: Relationship between diapause development and coloration changes in brown-winged green bug, Plautia stali Scott (Heteroptera: Pentatomidae). Jpn. J. Appl. Entomol. Zool. 31: 285-290. [in Japanese, English abstr.]

Masaki S. 1980: Summer diapause. Annu. Rev. Entomol. 25: $1-25$. 
NaKamura K. \& Numata H. 1997: Seasonal life cycle of Aelia fieberi (Hemiptera: Pentatomidae) in relation to the phenology of its host plants. Ann. Entomol. Soc. Am. 90: $625-630$.

Nakamura K. \& Numata H. 1998: Alternative life cycles controlled by temperature and photoperiod in the oligophagous bug, Dybowskyia reticulata. Physiol. Entomol. 23: 69-74.

NaKamura K. \& Numata H. 1999: Environmental regulation of adult diapause of Graphosoma rubrolineatum (Westwood) (Heteroptera: Pentatomidae) in southern and northern populations of Japan. Appl. Entomol. Zool. 34: 323-326.

NoDA H. \& IsHII T. 1981: Effect of photoperiod and temperature on the ovarian development of the white-spotted stink bug, Eysacoris ventralis (Heteroptera: Pentatomidae). Jpn. J. Appl. Entomol. Zool. 25: 33-38. [in Japanese, English abstr.]

NoDA T. 1984: Short day photoperiod accelerates the oviposition in the oriental green stink bug, Nezara antennata Scott (Heteroptera: Pentatomidae). Appl. Entomol. Zool. 19: 119-120.

Numata H. \& Hidaka T. 1982: Photoperiodic control of adult diapause in the bean bug, Riptortus clavatus Thunberg (Heteroptera: Coreidae). I. Reversible induction and termination of diapause. Appl. Entomol. Zool. 17: 530-538.

Numata H. \& Kobayashi S. 1994: Threshold and quantitative photoperiodic responses exist in an insect. Experientia 50: 969-971.

Numata H. \& Yamamoto K. 1990: Feeding on seeds induces diapause in the cabbage bug, Eurydema rugosa. Entomol. Exp. Appl. 57: 281-284.
Panizzi A.R., Schaefer C.W. \& Natuhara Y. 2000a: Broadheaded bugs (Alydidae). In: Schaefer C.W. \& Panizzi A.R. (eds.): Heteroptera of Economic Importance. CRC Press, Boca Raton, pp. 321-336.

Panizzi A.R., McPherson J.E., James D.G., Javahery M. \& McPierson R.M. 2000b: Stink bugs (Pentatomidae). In: Schaefer C.W. \& Panizzi A.R. (eds): Heteroptera of Economic Importance. CRC Press, Boca Raton, pp. 421-474.

TAUBER M.J. \& TAUBBer C.A. 1972: Geographical variation in critical photoperiod and in diapause intensity of Chrysopa carnea (Neuroptera). J. Insect Physiol. 18: 25-29.

TAUBBER M.J. \& TAUUBER C.A. 1977: Adaptive mechanisms underlying univoltinism in insects. Proc. XII Int. Conf. Chronobiol. The Publishing House Il Ponte, Milan, pp. 639-642.

Tauber M.J., Tauber C.A. \& Masaki S. 1986: Seasonal Adaptations of Insects. Oxford University Press, New York, 411 pp.

Tond J.W. 1989: Ecology and behavior of Nezara viridula. Annu. Rev. Entomol. 34: 273-292.

Tomokuni M., Yasunaga T., Takai M., Yamashita I., KawaMura M. \& KaWasawa T. 1993: A Field Guide to Japanese Bugs: Terrestrial Heteropterans. Zenkoku Noson Kyoiku Kyokai, Tokyo, 380 pp. [in Japanese]

YANo S. \& OHSAKI N. 1993: The phenology and intrinsic quality of wild crucifers that determine the community structure of their herbivorous insects. Res. Popul. Ecol. 35: 151-170.

Received November 9, 2001; revised January 14, 2002; accepted May 13, 2002 